\title{
Memories, performativities and (un)learning in design
}

\section{Doris Allhutter}

Austrian Academy of Sciences

Institute of Technology

Assessment

Strohgasse $45 / 5$

1030 Vienna, Austria

doris.allhutter@oeaw.ac.at

\section{Abstract}

This position paper discusses relations between

discourse, memories and performativity in design. It suggests making use of the concept of materialdiscursive performativity to investigate how design and societal hegemonies are co-emergent. In design practice, collective deconstruction of experiences and memories can provide a source for opening spaces of action to trigger (un) learning and the dislocation of established ways-of-doing.

\section{Keywords}

Material-discursive performativity in ICT design,

mundane experiences and memories in work practices, societal hegemonies, collective deconstruction, STS

ACM Classification Keywords

D.2.10 Design: Methodologies

\section{General Terms}

Design, Human Factors

\section{I ntroduction}

Research on material-discursive reconfigurings in

technology design/use refers to the ongoing

construction of social categories such as class, age, gender, ethnicity, ability, of related subjectivities, 
practices and power relations. These categories have been crucial in researching how socio-technical

practices emerge from cultural processes of negotiation and meaning construction and how practices and identities come into being with technology design and use. Enlightening examples are research on biases in computer science and related applied fields [e.g. 1,21], the inscription of user representations in terms of attributed competencies, actions and responsibilities [e.g. 2,17], and research on how design choices and user practices interact with users' self-representations and identities [e.g. 14,20]. In this spirit, value-based design approaches and critical design approaches, ${ }^{1}$ in one way or the other, have taken into account how discourses unfold in design practices and - explicitly or implicitly - have referred to various concepts of discursivity and discursive performativity. In reference to scholars such as Haraway, Suchman and Barad, an emerging strand of research highlights the ways in which situated, embodied design practices configure new alignments between the social and the material, and thus focuses on entangled design/use-practices as material-discursive processes: e.g, Baka and Scott [7] have investigated how a set of assumptions and related discourses define an algorithm that develops

intransparent agentive capacities; van der Velden and Mörtberg [19] have elaborated on the relationship of gender and technology and discuss the methodological consequences of 'designing for gender when design and gender, and their relations, are emergent' [see also 10]. Furthermore, Mackenzie $[15,16]$ has described

1 In contrast to value-based approaches, critical design approaches do not aim to establish pre-defined values but stress the need for critical reflection of the values inscribed to each design project [11] coding as a materially articulated cultural practice that is relevant to the 'performativity of power'.

Making use of the concept of material-discursive performativity in design research and practice-based ICT design, my research focuses on the reproduction of power by tracing the performativity of hegemonic societal discourses and their co-materialization with (normative) technological phenomena [4,5]. After a brief introduction into the concept and its socio-political implications, I will suggest that disclosing entangled performativities in design processes can open spaces for action and inventiveness. Thinking about identity and performativity has to consider the collective and structural dimensions of imaginaries and practices. Thus, as I will eventually discuss, deconstructing collectively shared experiences and memories that unfold in collaborative design processes and established ways-of-doing can provide a useful resource for considering and dislocating modes of becoming and emergence.

\section{Political implications of 'performativities'}

Foucault and Butler have illustrated how powerful

discourses, discursive practices and objectifications of discursive practices knit together and thereby produce and reproduce identities and dispositifs. ${ }^{2}$ 'Discourse does not refer to linguistic or signifying systems, grammars, speech acts, or conversations. [...] Discourse is not what is said; it is that which constrains and enables what can be said' [8:819]. The concept of performativity has played a crucial role in

understanding the processes through which hegemonic

2 A net of interwoven structural mechanisms and knowledge practices which maintain the exercise of power. 
discourses are enacted and become effective in shaping subjectivities and their relations within society.

Discursive practices are performative, i.e., they do not merely describe but produce the 'subjects' and 'objects' of knowledge practices; in this spirit, they enact sociotechnical relations. As Butler has illustrated, discursive practices and their materialisations - or, in Haraway's words, 'materialized reconfigurations' produce and reproduce societal hegemonies and power relations. ${ }^{3}$ Thus, the concept of performativity denotes power's mode of action. Barad's [9] materialistic elaboration of the concept shifts the focus from a discursive account, which is linked to the paradigm of co-construction of society and technology, to the notion of co-materialization. She criticizes that the focus on the social constructedness of bodies/materiality in fact neglects the question of 'how matter comes to matter'. In her elaboration of 'agential realism', Barad equally takes into account the agency of materiality or material phenomena.

On this background, a socio-political perspective to technical design (practice and theory) needs to consider the reconfiguration of power relations in intertwined epistemic and everyday work practices, and, borrowing Barad's terminology, the 'intra-action' of material phenomena with discursive socio-technological practices. The political dimension of ICT design cannot be framed as a set of predefined goals to be implemented; it is framed as a refiguring of sociotechnical relations that considers distributed agencies, thus including agential capacities of discursive-material relations.

\footnotetext{
3 For a comparison of different conceptions of performativity see [8]
}

Using the concept of performativity in $\mathrm{HCl}$ implies an infeasibility to design for human-machine interaction that inherently effects pre-defined emancipative use practices. Rather, the concept carries a potential to understand the way in which the sociomaterial practice of design, understood as a process of collective repetitions (of sociomaterial relations) and displacements within those repetitions, 1) reproduces modes of power and 2) shares re-enactments of performative discourses with use practices. A brief example from my own research may make this more comprehensible: Butler's theorisation of the reenactment of gender difference as a performative act has inspired scholars in STS and applied fields to research how gender and technological artefacts coemerge. The approach relates the unfolding of performative discourses of gender difference in design processes to gendered use practices. This relation is not causal though. Rather, gender difference is reenacted in design/use practices on the basis of collectively shared everyday discourses that implicitly negotiate relations such as the objective/subjective divide as gendered practices. Along with other reenactments of differences, gender difference is a discourse and a practice that entangles the threats of a dispositif - of a system of relations including knowledge practices and structural mechanisms.

Applying the concept of material-discursive performativity in design is based on a conception of developing computational artefacts as a situated and multi-dimensional process of (re-)figuring the relation between social meaning and material phenomena. This process is ideologically embedded, materially articulated and implicitly informed by societal discourses that become operative in collective everyday 
work practices of development teams: it consists of material-discursive practices. I suggest that taking account of material-discursive performativity has to consider the co-materialization of artefacts and societal hegemonies (e.g. normativity and hegemonies that are inscribed to development methods, processes and codings) as well as the identity-informing character of reiterated everyday practices. Such a perspective is to offer a way to make visible and thereby negotiable who (in/formal hierarchies) and what (ideological framings, discursive hegemonies; epistemic values; materialdiscursive relationalities) is given normative power on the basis of which societal values and socio-

technological imaginaries (e.g. re-enactments of societal differences, such as gender and class differences, and of epistemic dichotomies, such as the objective/subjective divide)

\section{Opening spaces of inventiveness}

Thinking about performativity is closely related to considering how capacities for action are currently figured at the human-machine interface, and how they might be imaginatively and materially reconfigured', as Suchman has suggested [18:1]. This means, that eventually, my aim of referring to Barad's materialist ontology and her linked concept of agency is to elaborate on how to take account of distributed agencies with the objective of opening spaces for action for designers. Such spaces, I suggest, carry a potentia to reconfigure material-discursive phenomena in a counter-hegemonic or subversive way. As van der Velden and Mörtberg [19:18) emphasize, design 'becomes an ongoing negotiation between our need to do justice [...] and the awareness that we are not able to know the effects of our design decisions. [...] we need to look careful at the iterations (visions, scenarios, specifications, abstractions, categories, prototypes, etc.) in the design process. Each iteration is an intra-action in which decisions are made about who and what matters and what may emerge out of the next intra-action.'

\section{Experiences and memories}

Still open remain the questions of how design teams can empower themselves to make visible and deconstruct how their practices are entangled with performative discourses and how understanding material-discursive intra-actions is conducive to widening their capacities for action.

Taking everyday work practices as an important site of reiteration and dislocation, I suggest that mundane experiences and memories are a main resource for researching and intervening into the 'doings' of performativities. The way experiences and memories inform design processes, has something to say about how designers have appropriated social structures and hegemonic knowledge practices. They are part of collective subjectivation processes that translate into work practices and their materialisations and vice versa. In reference to Haug [12], experiences may be seen as lived practice in the memory of a selfconstructed identity or emerging subjectivity. Memories structure the process whereby subjects perceive any given situation. They are fragmented and contradictory; their meaning is continually reconstructed and, in this sense, memories are essential for individual and collective sense-making in the present. Subjects integrate contradicting experiences and therefore interpret, transform and reconstruct their memories. Consequently, Haug argues that deconstructing and comparing written memories 
can be used as a source for disclosing collective meaning constructions. Deconstruction questions the ontological coherence of identities, totalities or concepts and thus the normativity of discourses and practices that surround them. It reveals the

constructedness of seemingly 'natural' sense-making; it seeks absences and silenced contradictions and aims at denaturalizing self-evident causalities. In design

practice, deconstructing memories enables the analysis of performative discourses that designers have appropriated in their professional field, through public discourses and everyday experiences. It provides an approach to trace how designers - in a collective process of constructing matter and meaning interconnect their professional know-how with practical ways of problem-solving that are co-shaped by hegemonic everyday discourses and sociotechnical apparatuses. Discourses gain performativity in that they have the capacity to occupy collective imaginaries, to (re-) produce collectively shared realities. In light of this, it makes sense to suggest a collective procedure of deconstruction that creates space for negotiating these realities. ${ }^{4}$

The question of how to make use of a materialist account of performativity in design practice is not easy to resolve. The idea to get hold of material phenomena by resorting to experiences and memories can to some extent be pursued by tracing the designers' collective 'storying of materiality'. ${ }^{5}$ For example, Mackenzie

${ }^{4}$ For a detailed description of such a methodical approach see

${ }^{5}$ This idea was inspired by a conversation between Haraway, Barad and Suchman in a seminar on 'Feminist Technoscience Studies' at Lancaster University in May 2011.
[16:7] has described 'the specificities of code as a material articulated, felt, shaped and changed in practices'. According to the particular practices in actual design processes, I suggest that it makes sense to collectively investigate, for example, how specifications and codings intra-act or how systems architectures relate (social) categories to each other.

Barad [9] has described how discursive and material phenomena exist in a relation of mutual 'exterioritywithin'. Entangling the described performativities considers the 'becoming with' technologies and the coemergence of subjectivities and artefacts. The outcome of such an approach is indeterminate in terms of the inherent agentive capacities of the resulting artefact. However, I suggest that collectively experiencing (via deconstruction) the political implications and identityinforming mechanisms of one's collaborative work practices re-articulates memories and displaces modes of meaning making.

\section{(Un) learning}

What we are learning from experiences and latently guiding discourses is deeply inscribed in embodied everyday practices and our cultural beliefs and valuesystems [12]. At the same time, this means that learning as a social practice strongly relies on processes of unlearning of implicit sense-making (e.g. of inhibitory norms, values and exclusions) and of consciously re-negotiating meaning $[13,6]$. Getting back to Suchman's suggestion to imaginatively and materially reconfigure capacities for action at the human-machine interface, I claim that enabling collective moments of gradual dislocation has the capacity to open up new ways of 'becoming with' and co-emergence. 
[1] Adam, A. Artificial Knowing: Gender and the Thinking Machine. Routlegde, New York, 1998.

[2] Akrich, M. User Representations: Practices, Methods and Sociology. In Rip, A., Misa, T.J., and Schot, J. (eds.) Managing Technology in Society. The Approach of Constructive Technology Assessment. Pinter Publishers, London, New York, 1995, 167-184.

[3] Allhutter, D. Mind Scripting: a Method for Deconstructive Design. Science, Technology \& Human Values, Online First March 13 (2011).

[4] Allhutter D. The social and its political dimension in software design. In Ess, C. and Hagengruber, R. (eds.) The Computational Turn: Past, Presents, Futures?, Münster, 2011, 290-292.

[5] Allhutter D. Performativity in software design: a socio-political approach to everyday work practices, STS-Mixtures, Lancaster University.

http://www. lancs.ac.uk/fass/centres/css/event/3721/.

[6] Allhutter D. and Hofmann R. Deconstructive Design as an Approach to opening Trading Zones. In Vallverdú, J. (ed.). Thinking Machines and the Philosophy of Computer Science: Concepts and Principles, Hershey, New York, 2010, 175-192.

[7] Baka, V. and Scott, S.V. Algorithmic (re)configurations: exploring the 'becoming' of social media in the travel sector. Proc. PROS International Symposium (2011).

[8] Barad, K. Posthumanist Performativity. Towards an understanding of how matter comes to matter. Signs. J ournal of Women in Culture and Society 28, 3 (2003), 801-831.

[9] Barad, K. Meeting the Universe Halfway: Quantum Physics and the Entanglement of Matter and Meaning. Duke University Press, Durham, London, 2007.

[10] Bath, C. Searching for Methodology: Feminist Technology Design in Computer Science. Online Proc. Gender \& ICT (2009).

http://elib.suub.uni-bremen.de/ip/docs/00010427.pdf
[11] Harrison, S., Sengers, P., and Tatar, D. Making Epistemological Trouble: Third-Paradigm $\mathrm{HCl}$ as Successor Science. Interacting with Computers 23, 5 (2011), 385-292.

[12] Haug, F. Erinnerungsarbeit - ein Leitfaden zur Methode. In Haug, F. (ed.), Vorlesungen zur Einführung in die Erinnerungsarbeit. Argument, Hamburg, 1999, 199-227.

[13] Hedberg, B. How organizations learn and unlearn. In Nystrom, P.C. and Starbuck W.H. (eds.) Handbook of Organizational Design, Vol. 1. Oxford University Press, New York, 1981, 3-27.

[14] Light, A. HCl as heterodoxy. Technologies of identity and the queering of interaction with computers. Interacting with Computers 23, 5 (2011), 430-438.

[15] Mackenzie, A. The Performativity of Code. Software and Cultures of Circulation. Theory, Culture \& Society 22, 1 (2005), 71-92.

[16] Mackenzie, A. Cutting Code. Software and Sociality. Peter Lang, New York, 2006.

[17] Oudshoorn, N. and Pinch, T. (eds.) How Users Matter: The Co-Construction of Users and Technology. MIT Press, Massachusetts, 2003.

[18] Suchman, L. Agencies in Technology Design:

Feminist Reconfigurations. Online Proc. Gender \& ICT (2009). http://www.informatik.uni-bremen.de/soteg/ gict2009/proceedings/GICT2009 Suchman.pdf

[19] van der Velden, M. and Mörtberg, C. Between Need and Desire: Exploring Strategies for Gendering Design. Science, Technology \& Human Values, OnlineFirst March 13 (2011).

[20] Van House, N. A. Feminist $\mathrm{HCl}$ meets facebook: Performativity and social networking sites. Interacting with Computers 23, 5 (2011), 422-429.

[21] Zorn, I., Maaß, S., Rommes, E., Schirmer, C., and Schelhowe, H. (eds.) Gender Designs IT: Construction and Deconstruction of Information Society Technology. VS, Wiesbaden, 2007 